\title{
Volumetric and functional assessment of the left atrium in young competitive athletes without left ventricular hypertrophy: the MAGYAR-Sport Study
}

\author{
Attila NEMES ${ }^{1}$, Péter DOMSIK ${ }^{1}$, Anita KALAPOS ${ }^{1}$, Andrea OROSZ ${ }^{2}$, Mónika OSZLÁNCZI ${ }^{1}$, \\ László TÖRÖK ${ }^{3,4}$, László BALOGH ${ }^{5}$, János MÁRTON ${ }^{4}$, Tamás FORSTER ${ }^{1}$, Csaba LENGYEL ${ }^{6}$
}

${ }^{1}$ Second Department of Medicine and Cardiology Centre, Albert Szent-Györgyi Clinical Center, Faculty of Medicine, University of Szeged, Szeged, Hungary; 2Department of Pharmacology and Pharmacotherapy, Faculty of Medicine, University of Szeged, Szeged, Hungary; ${ }^{3}$ Department of Traumatology, Albert Szent-Györgyi Clinical Center, Faculty of Medicine, University of Szeged, Szeged, Hungary; ${ }^{4}$ Department of Sports Medicine, Albert Szent-Györgyi Clinical Center, Faculty of Medicine, University of Szeged, Szeged, Hungary; 5 Intitute of Physical Education and Sports Science, Gyula Juhász Faculty of Education, University of Szeged, Szeged, Hungary; ${ }^{6}$ First Department of Medicine, Albert Szent-Györgyi Clinical Center, Faculty of Medicine, University of Szeged, Szeged, Hungary

*Corresponding author: Attila Nemes, Second Department of Medicine and Cardiology Center, Faculty of Medicine, Albert Szent-Györgyi Clinical Center, University of Szeged, Semmelweis street 6, P.O. Box 427, H-6725 Szeged, Hungary. E-mail: nemes.attila@med.u-szeged.hu

\section{A B S T R A C T}

BACKGROUND: Left atrial (LA) remodeling may be regarded as a physiologic adaptation to exercise conditioning. Three-dimensional speckle tracking echocardiography (3DSTE) is a new promising tool for volumetric and functional characterization of the LA. The present study was undertaken to assess adaptive changes in LA volumes and functional properties respecting cardiac cycle in young competitive athletes without left ventricular hypertrophy (LVH) by detailed 3DSTE assessment.

METHODS: The study group consisted of 20 young elite basketball and handball players (mean age: $28.1 \pm 10.1$ years, 8 men) without LVH, their results were compared to 23 age- and gender-matched non-sportive healthy controls (mean age: $31.7 \pm 8.5$ years, 11 men. All subjects had undergone standard transthoracic two-dimensional Doppler echocardiographic study with 3DSTE.

RESULTS: Increased systolic maximum $(66.5 \pm 13.6 \mathrm{~mL} v s .38 .5 \pm 8.6 \mathrm{~mL}, \mathrm{P}<0.0001)$ and diastolic minimum $(36.7 \pm 8.1 \mathrm{~mL} v \mathrm{~s} .17 .5 \pm 5.8 \mathrm{~mL}$, $\mathrm{P}<0.0001)$ and preatrial contraction $(46.2 \pm 10.1 \mathrm{~mL}$ vs. $26.2 \pm 7.8 \mathrm{~mL}, \mathrm{P}<0.0001)$ LA volumes could be demonstrated in athletes. Total $(29.7 \pm 9.0$ $\mathrm{mL} v$ s. $20.7 \pm 5.0 \mathrm{~mL}, \mathrm{P}=0.0002)$ and passive $\mathrm{LA}$ stroke volumes $(19.8 \pm 8.7 \mathrm{~mL} v s .12 .4 \pm 4.6 \mathrm{~mL}, \mathrm{P}=0.0009)$ were increased, while total ( $44.2 \pm 9.1$ $\mathrm{mL}$ vs. $54.2 \pm 9.4 \mathrm{~mL}, \mathrm{P}=0.001)$ and active LA emptying fractions $(20.6 \pm 11.8 \%$ vs. $31.9 \pm 8.7 \%, \mathrm{P}=0.0008)$ proved to be decreased in athletes as compared to controls. Active LA stroke volume $(9.9 \pm 5.8 \mathrm{~mL} v s .8 .3 \pm 3.3 \mathrm{~mL}, \mathrm{P}=0.29)$ and passive LA emptying fraction $(29.1 \pm 10.6 \mathrm{~mL} v s$. $32.6 \pm 11.2 \mathrm{~mL}, \mathrm{P}=0.31)$ did not differ between the groups. Only circumferential global $(21.1 \pm 7.7 \%$ vs. $27.6 \pm 9.9 \%$, $\mathrm{P}=0.02)$ and mean segmental $(26.1 \pm 7.1 \%$ vs. $35.7 \pm 12.0 \%, \mathrm{P}=0.003)$ peak LA strains proved to be significantly reduced in athletes as compared to controls.

CONCLUSIONS: 3DSTE-derived increased cyclic LA volumes and specific alterations in LA functional properties could be demonstrated in young competing athletes which is most likely a physiologic consequence of a global cardiac adaptation to intensive and chronic training.

(Cite this article as: Nemes A, Domsik P, Kalapos A, Orosz A, Oszlánczi M, Török L, et al. Volumetric and functional assessment of the left atrium in young competitive athletes without left ventricular hypertrophy: the MAGYAR-Sport Study. J Sports Med Phys Fitness 2017;57:900-6. DOI: $10.23736 / \mathrm{S} 0022-4707.16 .06265-4)$

Key words: Heart atria - Heart function tests - Imaging, three-dimensional - Echocardiography - Sports.

$I^{n}$ ntensive athletic conditioning is associated with physiological adoptation of the heart of an athlete. ${ }^{1}$ Changes in left ventricular (LV) size and mass are well- known recognized features in highly trained athletes. ${ }^{2}$ Moreover, left atrial (LA) remodeling may be regarded as a physiologic adaptation to exercise conditioning, as 


\section{COPYRIGHT $^{(} 2017$ EDIZIONI MINERVA MEDICA}

well.3-5 Three-dimensional (3D) speckle-tracking echocardiography (3DSTE) represents a promising, non-invasive, simple and reproducible technique for detailed assessment of LA morphology and function including volumetric and strain assessments at the same time from the same acquired 3D dataset. ${ }^{6}$ Due to well-known interaction between intensive training-induced LV hypertrophy (LVH) and LA function, ${ }^{1}$ the present study was undertaken to assess adaptive changes in LA volumes and functional properties in elite competitive athletes without LVH by detailed 3DSTE assessment and to compare their results to age- and gender-matched nonathletic healthy volunteers.

\section{Materials and methods}

\section{Patients population}

The study group consisted of 20 young elite basketball and handball players (mean age: $28.1 \pm 10.1$ years, 8 men) without LVH. Training volume and intensity were similar to that one previously described. ${ }^{7}$ Echocardiographic examination was performed at the beginning of the low-training period in most of cases (16 subjects). During the low-training period, athletes trained for about $18 \mathrm{~h} /$ week including sprinting conditioning and high-volume/low-intensity running. Training also consisted of 2 resistance-training sessions/ week at high-moderate workload. During the peak training period, athletes trained for $12 \mathrm{~h} /$ week and had one or two matches a week. Low-volume/high-intensity running, sprinting and tactical-technical drilling were also performed at this period. Athletes trained 1-2 resistance-training sessions per week at moderate workload as well. The mean previous years of training proved to be $16 \pm 8$ years. Athletes with LVH were excluded from the present study. LVH was considered if LV mass index $>134 \mathrm{~g} / \mathrm{m}^{2}$ in men and $110 \mathrm{~g} / \mathrm{m}^{2}$ in women. ${ }^{8}$ Their results were compared to 23 age- and gender-matched non-athletic healthy controls (mean age: $31.7 \pm 8.5$ years, 11 men). All athletes and matched healthy controls were examined by two-dimensional Doppler echocardiography and 3DSTE. Regarding to the task force classification of the American College of Cardiology considering dynamic and static component of their training, our athletes proved to be high dynamic/moderate static (Group CII) (>70\% VO $\mathrm{VO}_{2 \max }, 20-50 \%$ voluntary contraction) ${ }^{9}$
A special study has been organized at our department to examine diagnostic and prognostic significance of 3DSTE-derived variables in elite athletes named MAGYAR-Sport Study (Motion Analysis of the heart and Great vessels bY three-dimensionAl speckle-tRacking echocardiography in Sportmen, magyar means Hungarian in Hungarian language). All subjects provided written informed consent to participate, and ethics approval was granted by the local institutional human research committee approved the study which complied with the 1975 Declaration of Helsinki.

\section{Two-dimensional, Doppler and tissue Doppler echocar- diography}

All echocardiographic studies including M-mode, 2-dimensional, Doppler and tissue Doppler studies were performed with a commercially available echocardiography equipment (Toshiba ArtidaTM; Toshiba Medical Systems, Tokyo, Japan). A PST-30SBP phased-array transducer was used for routine measuments. LV dimensions were calculated from the standard M-mode images obtained at the parasternal long-axis views. ${ }^{10}$ Visual grading of valvular regurgitations were confirmed by colour Doppler echocardiography. Early diastolic (E) and atrial (A) wave velocities and their ratio (E/A) were measured by pulsed-wave Doppler-derived transmitral velocity assessments. ${ }^{10}$

\section{DSTE-derived data acquisition and quantitative anal- ysis}

A special matrix phased-array transducer $(2,5 \mathrm{MHz}$ PST-25SX; Toshiba Medical Systems, Tokyo, Japan) was used for the acquisition of $3 \mathrm{D}$ echocardiographic datasets from the apical view. ${ }^{6}$ Six R-wave-triggered subvolumes acquired for 6 consecutive cardiac cycles during one breath-hold were combined to form the pyramid-shape 3D full volume including LA. The 3D Wall Motion Tracking software version 2.7 (Toshiba Medical Systems, Tokyo, Japan) was used for quantifications. Firstly, apical two- (AP2CH) and four-chamber $(\mathrm{AP} 4 \mathrm{CH})$ views and three short-axis views at different levels of the LA at end-diastole were automatically selected from the full volume 3D dataset by the software. After finding optimal nonforeshortened views, the reader set markers on orthogonal $\mathrm{AP} 2 \mathrm{CH}$ and $\mathrm{AP} 4 \mathrm{CH}$ views. 


\section{COPYRIGHT $^{\odot} 2017$ EDIZIONI MINERVA MEDICA}

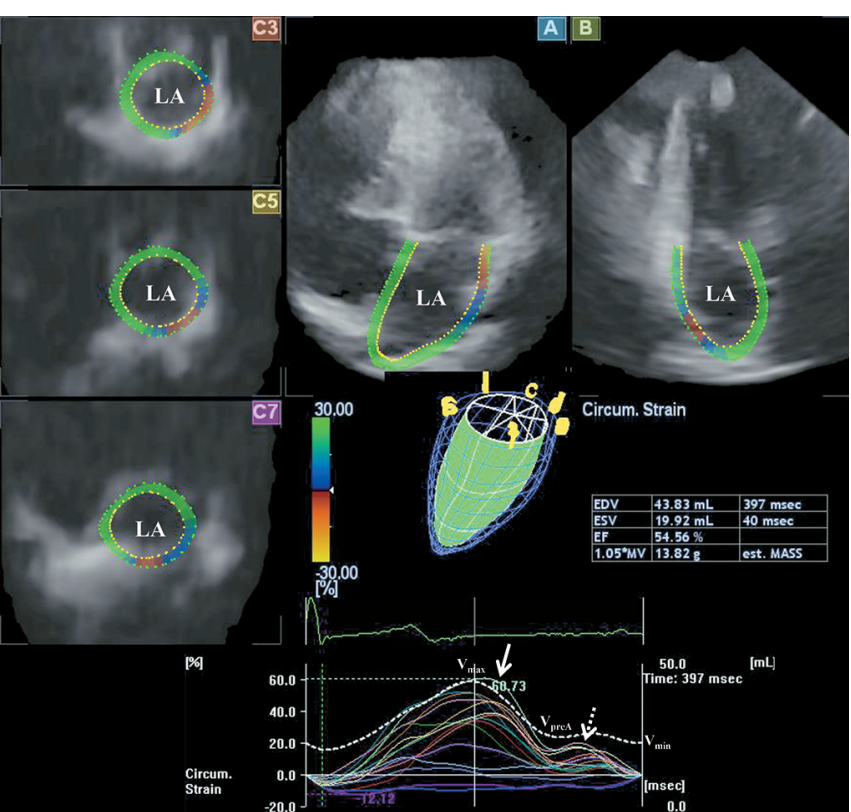

Figure 1.-Three-dimensional (3D) speckle-tracking echocardiographic assessment of the left atrium (LA) in an athlete is displayed. Apical fourchamber view (A), apical two-chamber view (B), short-axis view at basal (C3), midatrial (C5) and superior left atrial level (C7) are presented together with a $3 \mathrm{D}$ model of the LA and calculated volumetric data. Time - global LA volume (dashed line) - and time - LA circumferential segmental strain curves (continuous lines) - could be demonstrated. Maximum $\left(\mathrm{V}_{\max }\right)$, minimum $\left(\mathrm{V}_{\min }\right)$ LA volumes and LA volume before atrial contraction $\left(\mathrm{V}_{\text {preA }}\right)$ could be measured together with peak strain (white arrow) and strain at atrial contraction (dashed arrow).

EDV: end-diastolic volume; ESV: end-systolic volume; EF: ejection fraction; LA: left atrium.

Firstly, the edge of septum-mitral ring was traced, then markers were set in a counterclockwise rotation around the LA to the edge of the lateral wall-mitral ring. LA appendage and pulmonary veins were excluded from the LA cavity during evaluations. Finally, the 3D endocardial surface of the LA was automatically reconstructed and tracked in 3D space throughout the entire cardiac cycle (Figure 1).

\section{DSTE-derived LA volumetric assessements}

LA volumes were measured echocardiographically at the time of mitral valve opening (maximum LA volume, $\mathrm{V}_{\max }$ ), at the onset of atrial systole ( $\mathrm{p}$ wave on electrocardiography $=\mathrm{V}_{\text {preA }}$ ), and at mitral valve closure (minimum LA volume, $\left.\mathrm{V}_{\min }\right)$. The following LA functional parameters were calculated:11
- systolic reservoir function:

- LA total stroke (emptying) volume $(\mathrm{TASV})=\left(\mathrm{V}_{\max }-\mathrm{V}_{\min }\right)$;

- LA total emptying fraction $(\mathrm{TAEF})=\mathrm{TASV} /$ $\mathrm{V}_{\text {max }}$;

- early diastolic conduit function:

- LA passive stroke (emptying) volume $(\mathrm{PASV})=\mathrm{V}_{\max }-\mathrm{V}_{\text {preA }}$;

- LA passive emptying fraction $(\mathrm{PAEF})=$ $\mathrm{PASV} / \mathrm{V}_{\max }$;

- late diastolic booster pump function (active contraction phase):

- LA active stroke (emptying) volume $(\mathrm{AASV})=\mathrm{V}_{\text {preA }}-\mathrm{V}_{\text {min }}$

- LA active emptying fraction $(\mathrm{AAEF})=\mathrm{AASV} /$ $\mathrm{V}_{\text {preA }}$.

All measurements were averaged over 3 cardiac cycles.

\section{DSTE-derived LA strain measurements}

3DSTE allows calculation of several unidirectional (radial [RS], longitudinal [LS] and circumferential [CS] strains) and complex (area [AS] and 3D [3DS] strains) strains the same acquired 3D dataset. ${ }^{6}$ Peak strains (featuring LA reservoir phase) and strains at atrial contraction (featuring LA contraction phase) were calculated in each case. The software enables measurement of global (including all the data related to the heart chamber), segmental (using a 16-segment model elaborated for the LV) and mean segmental (average of calculated segmental) strains. LA regional strains (basal, midatrial and superior) were calculated from segmental strain values. In a recent study good inter- and intraboserver variability could be demonstrated in the assessment of these 3DSTE-derived uni- and multidirectional LA strains. ${ }^{12}$

\section{Stastical analysis}

Continuous data are expressed as mean \pm standard deviation, while categorical data are summarized as a count and percentage. Categorical variables were examined by Fisher's Exact Test and $\chi^{2}$ test, while continuous ones were assessed with the unpaired Student $t$-test. Statistical significance was defined with a probability value $<0.05$. Data analyses were performed using Medcalc software (MedCalc, Mariakerke, Belgium). 


\section{COPYRIGHT $^{\odot} 2017$ EDIZIONI MINERVA MEDICA}

THE MAGYAR-SPORT STUDY

NEMES

Results

\section{Clinical data}

Neither competitive athletes, nor healthy controls had known disease or received medications. Routine twodimensional Doppler echocardiography showed normal results without valvular alterations (Table I).

\section{DSTE-derived LA volumes and volume-based func- tional properties}

Increased systolic $\mathrm{V}_{\max }(66.5 \pm 13.6 \mathrm{~mL} v s .38 .5 \pm 8.6$ $\mathrm{mL}, \mathrm{P}<0.0001)$ and diastolic $\mathrm{V}_{\min }(36.7 \pm 8.1 \mathrm{~mL}$ vs. $17.5 \pm 5.8 \mathrm{~mL}, \mathrm{P}<0.0001)$ and $\mathrm{V}_{\text {preA }}(46.2 \pm 10.1 \mathrm{~mL} v s$. $26.2 \pm 7.8 \mathrm{~mL}, \mathrm{P}<0.0001)$ LA volumes could be demonstrated in athletes. TASV $(29.7 \pm 9.0 \mathrm{~mL}$ vs. $20.7 \pm 5.0$ $\mathrm{mL}, \mathrm{P}=0.0002)$ and PASV $(19.8 \pm 8.7 \mathrm{~mL}$ vs. $12.4 \pm 4.6$

TABLE I.-Two-dimensional echocardiographic data of athletes and controls.

\begin{tabular}{lccl}
\hline & $\begin{array}{c}\text { Athletes } \\
(\mathrm{N} .=20)\end{array}$ & $\begin{array}{c}\text { Controls } \\
(\mathrm{N} .=18)\end{array}$ & P value \\
\hline Left atrium $(\mathrm{mm})$ & $37.8 \pm 4.0$ & $33.9 \pm 4.1$ & 0.006 \\
LV end-diastolic diameter $(\mathrm{mm})$ & $49.2 \pm 3.5$ & $48.4 \pm 6.3$ & 0.60 \\
LV end-diastolic volume $(\mathrm{ml})$ & $110.4 \pm 22.3$ & $104.2 \pm 21.1$ & 0.36 \\
LV end-systolic diameter $(\mathrm{mm})$ & $29.3 \pm 2.5$ & $29.9 \pm 3.9$ & 0.58 \\
LV end-systolic volume $(\mathrm{mL})$ & $32.8 \pm 6.9$ & $34.4 \pm 10.3$ & 0.54 \\
Interventricular septum $(\mathrm{mm})$ & $7.8 \pm 1.3$ & $8.8 \pm 2.2$ & 0.07 \\
LV posterior wall $(\mathrm{mm})$ & $8.0 \pm 1.2$ & $8.9 \pm 2.4$ & 0.13 \\
LV ejection fraction $(\%)$ & $71.4 \pm 5.3$ & $67.1 \pm 6.9$ & 0.03 \\
E/A & $1.88 \pm 031$ & $1.30 \pm 0.17$ & 0.05 \\
\hline
\end{tabular}

TABLE II.-Comparison of 3DSTE-derived peak global and mean segmental left atrial strain parameters between athletes and controls

\begin{tabular}{lccc}
\hline & $\begin{array}{c}\text { Athletes } \\
(\mathrm{N} .=20)\end{array}$ & $\begin{array}{c}\text { Controls } \\
(\mathrm{N} .=23)\end{array}$ & P value \\
\hline Peak global strains & & & \\
$\quad$ Radial strain (\%) & $-17.9 \pm 4.8$ & $-19.8 \pm 10.9$ & 0.48 \\
Circumferential strain (\%) & $21.1 \pm 7.7$ & $27.6 \pm 9.9$ & 0.02 \\
Longitudinal strain (\%) & $26.2 \pm 7.8$ & $26.0 \pm 7.1$ & 0.92 \\
3D strain (\%) & $-10.0 \pm 4.1$ & $-12.0 \pm 10.0$ & 0.42 \\
Area strain (\%) & $53.5 \pm 16.7$ & $58.7 \pm 17.6$ & 0.33 \\
Peak mean segmental strains & & & \\
Radial strain (\%) & $-19.6 \pm 4.4$ & $-21.8 \pm 8.4$ & 0.29 \\
Circumferential strain (\%) & $26.1 \pm 7.1$ & $35.7 \pm 12.0$ & 0.003 \\
Longitudinal strain (\%) & $28.2 \pm 7.2$ & $31.7 \pm 6.7$ & 0.11 \\
3D strain (\%) & $-13.9 \pm 3.7$ & $-15.1 \pm 6.6$ & 0.45 \\
Area strain (\%) & $59.0 \pm 15.7$ & $73.2 \pm 21.5$ & 0.06 \\
\hline 3DS: three-dimensional, 3DSTE: three-dimensional speckle-tracking echocardi- \\
ography
\end{tabular}

$\mathrm{mL}, \mathrm{P}=0.0009)$ proved to be increased, while TAEF (44.2 $\pm 9.1 \mathrm{~mL}$ vs. $54.2 \pm 9.4 \mathrm{~mL}, \mathrm{P}=0.001)$ and $\mathrm{AAEF}$ $(20.6 \pm 11.8 \mathrm{~mL}$ vs. $31.9 \pm 8.7 \mathrm{~mL}, \mathrm{P}=0.0008)$ were decreased in athletes as compared to controls. AASV (9.9 $\pm 5.8 \mathrm{~mL} v s . \quad 8.3 \pm 3.3 \mathrm{~mL}, \mathrm{P}=0.29)$ and $\mathrm{PAEF}$ $(29.1 \pm 10.6 \mathrm{~mL}$ vs. $32.6 \pm 11.2 \mathrm{~mL}, \mathrm{P}=0.31)$ did not differ between athletes and controls.

\section{DSTE-derived LA strain parameters}

Only peak global $(21.1 \pm 7.7 \%$ vs. $27.6 \pm 9.9 \%, \mathrm{P}=0.02)$ and mean segmental $(26.1 \pm 7.1 \%$ vs. $35.7 \pm 12.0 \%$, $\mathrm{P}=0.003$ ) peak LA-CS proved to be significantly reduced in athletes as compared to controls. All peak global, mean segmental and segmental LA strains and LA strains at atrial contraction are presented in Tables II-V.

\section{Discussion}

To the best of authors' knowledge this is the first time to demonstrate alterations in 3DSTE-derived LA

TABLE III.-Comparison of 3DSTE-derived peak regional left atrial strain parameters between athletes and controls.

\begin{tabular}{llll}
\hline & $\begin{array}{c}\text { Athletes } \\
(\mathrm{N} .=20)\end{array}$ & $\begin{array}{l}\text { Controls } \\
(\mathrm{N} .=18)\end{array}$ & P value \\
\hline Peak regional radial strains (RS) & & & \\
Basal RS (\%) & $-19.5 \pm 4.4$ & $-23.1 \pm 13.0$ & 0.24 \\
Midatrial RS (\%) & $-17.6 \pm 4.9$ & $-22.7 \pm 10.2$ & 0.05 \\
Apical RS (\%) & $-22.7 \pm 9.9$ & $-21.2 \pm 13.1$ & 0.67 \\
Peak regional circumferential & & & \\
strains (CS) & & & \\
Basal CS (\%) & $30.4 \pm 8.4$ & $39.7 \pm 10.7$ & 0.003 \\
Midatrial CS (\%) & $21.7 \pm 5.9$ & $30.9 \pm 10.2$ & 0.001 \\
Apical CS (\%) & $26.2 \pm 21.5$ & $29.8 \pm 19.4$ & 0.57 \\
Peak regional longitudinal strains & & & \\
(LS) & & & \\
Basal LS (\%) & $29.1 \pm 11.8$ & $17.5 \pm 8.4$ & 0.0006 \\
Midatrial LS (\%) & $36.5 \pm 13.8$ & $41.6 \pm 13.6$ & 0.22 \\
Apical LS (\%) & $14.6 \pm 7.1$ & $23.1 \pm 9.6$ & 0.002 \\
Peak regional 3D strains (3DS) & & & \\
Basal 3DS (\%) & $-14.4 \pm 4.1$ & $-17.6 \pm 12.0$ & 0.26 \\
Midatrial 3DS (\%) & $-11.6 \pm 4.1$ & $-15.1 \pm 8.6$ & 0.10 \\
Apical 3DS (\%) & $-16.4 \pm 8.6$ & $-15.4 \pm 9.9$ & 0.73 \\
Peak regional area strains (AS) & & & \\
Basal AS (\%) & $61.1 \pm 19.8$ & $55.6 \pm 17.7$ & 0.34 \\
Midatrial AS (\%) & $60.8 \pm 22.7$ & $80.3 \pm 23.2$ & 0.008 \\
Apical AS (\%) & $53.2 \pm 46.0$ & $63.9 \pm 39.9$ & 0.42 \\
\hline 3Ding
\end{tabular}

3D: three-dimensional; 3DS: three-dimensional strain; 3DSTE: three-dimensional speckle-tracking echocardiography; AS: area strain; CS: circumferential strain; LS: longitudinal strain; RS: radial strain. 


\section{COPYRIGHT $^{(} 2017$ EDIZIONI MINERVA MEDICA}

NEMES

THE MAGYAR-SPORT STUDY

TABLE IV.-Comparison of 3DSTE-derived global and mean segmental left atrial strain at atrial contraction parameters between athletes and controls.

\begin{tabular}{lccc}
\hline & $\begin{array}{c}\text { Athletes } \\
(\mathrm{N} .=20)\end{array}$ & $\begin{array}{c}\text { Controls } \\
(\mathrm{N} .=23)\end{array}$ & P value \\
\hline Global strains at atrial contraction & & & \\
$\quad$ Radial strain (\%) & $-5.7 \pm 4.0$ & $-7.1 \pm 7.4$ & 0.48 \\
Circumferential strain (\%) & $11.3 \pm 7.0$ & $11.2 \pm 10.2$ & 0.95 \\
Longitudinal strain (\%) & $6.4 \pm 4.7$ & $9.9 \pm 8.5$ & 0.11 \\
3D strain (\%) & $-4.7 \pm 4.3$ & $-5.2 \pm 5.1$ & 0.71 \\
Area strain (\%) & $18.0 \pm 12.3$ & $18.1 \pm 15.3$ & 0.98 \\
Mean segmental strains at atrial & & & \\
contraction & & & \\
Radial strain (\%) & $-8.3 \pm 3.2$ & $-8.3 \pm 4.9$ & 0.98 \\
Circumferential strain (\%) & $12.1 \pm 5.4$ & $13.5 \pm 9.1$ & 0.55 \\
Longitudinal strain (\%) & $7.5 \pm 3.9$ & $9.7 \pm 5.6$ & 0.15 \\
3D strain (\%) & $-6.8 \pm 2.2$ & $-6.6 \pm 4.4$ & 0.88 \\
Area strain (\%) & $22.4 \pm 10.2$ & $22.0 \pm 13.7$ & 0.92 \\
\hline
\end{tabular}

3DS: three-dimensional; 3DSTE: three-dimensional speckle-tracking echocardiography.

volumetric and functional properties in young competitive athletes. All cyclic LA volumes and LA stroke volumes in LA reservoir and conduit phases proved to be increased in athletes. Moreover, reduced LA emptying fractions in LA reservoir and active contraction phases could be demonstrated. In respect with strains, only peak global and mean segmental CSs, features of LA reservoir function, were found to be decreased in athletes, all other strains did not differ between the groups examined. However, some segmental strains showed significant differences between athletes and controls which could highlight our attentation on the importance of 3DSTE-derived detailed analysis. From LA strains at active contraction phase, only midatrial segmental LAAS strain at atrial contraction differed significantly.

The number of studies in which LA was assessed in athletes is increasing due to the more ready new echocardiographic methodologies and the increased scientific interest on this topic trying to understand its physiologic/pathophysiologic background. ${ }^{13}$ In a very early study it was indicated that former endurance athletes have an enlarged LA but a normal-sized LV. ${ }^{14}$ In a large population of highly trained athletes, a mild enlargement of LA volume index was relatively common and may be regarded as a physiologic adaptation to exercise conditioning. ${ }^{15}$ Enlarged LA dimension $\geq 40 \mathrm{~mm}$ was found in $20 \%$ of highly trained athletes in another study, with the upper limits of $45 \mathrm{~mm}$ in women and $50 \mathrm{~mm}$ in men distinguishing physiologic cardiac remodeling
TABLE V.-Comparison of 3DSTE-derived regional left atrial strain at atrial contraction parameters between athletes and controls.

\begin{tabular}{|c|c|c|c|}
\hline & $\begin{array}{l}\text { Athletes } \\
(\mathrm{N} .=20)\end{array}$ & $\begin{array}{l}\text { Controls } \\
(\mathrm{N} .=23)\end{array}$ & $P$ value \\
\hline \multicolumn{4}{|c|}{$\begin{array}{l}\text { Regional radial strains (RS) at } \\
\text { atrial contraction }\end{array}$} \\
\hline Basal RS (\%) & $-7.0 \pm 2.0$ & $-8.3 \pm 6.3$ & 0.39 \\
\hline Midatrial RS (\%) & $-7.5 \pm 4.4$ & $-8.3 \pm 5.4$ & 0.62 \\
\hline Apical RS (\%) & $-11.4 \pm 5.6$ & $-9.7 \pm 7.4$ & 0.39 \\
\hline \multicolumn{4}{|c|}{$\begin{array}{l}\text { Regional circumferential strains } \\
\text { (CS) at atrial contraction }\end{array}$} \\
\hline Basal CS (\%) & $12.6 \pm 5.6$ & $16.2 \pm 9.0$ & 0.14 \\
\hline Midatrial CS (\%) & $9.6 \pm 5.5$ & $12.0 \pm 8.2$ & 0.28 \\
\hline Apical CS (\%) & $15.1 \pm 14.7$ & $10.0 \pm 13.2$ & 0.24 \\
\hline \multicolumn{4}{|c|}{$\begin{array}{l}\text { Regional longitudinal strains } \\
\text { (LS) at atrial contraction }\end{array}$} \\
\hline Basal LS (\%) & $7.8 \pm 3.5$ & $6.3 \pm 5.1$ & 0.28 \\
\hline Midatrial LS (\%) & $7.3 \pm 5.8$ & $11.0 \pm 7.2$ & 0.07 \\
\hline Apical LS (\%) & $7.5 \pm 6.5$ & $11.1 \pm 9.8$ & 0.18 \\
\hline \multicolumn{4}{|c|}{$\begin{array}{l}\text { Regional 3D strains (3DS) at } \\
\text { atrial contraction }\end{array}$} \\
\hline Basal 3DS (\%) & $-6.7 \pm 2.5$ & $-6.5 \pm 5.8$ & 0.89 \\
\hline Midatrial 3DS (\%) & $-6.1 \pm 3.0$ & $-5.5 \pm 4.2$ & 0.63 \\
\hline Apical 3DS (\%) & $-8.0 \pm 5.4$ & $-8.3 \pm 6.6$ & 0.89 \\
\hline \multicolumn{4}{|c|}{$\begin{array}{l}\text { Regional area strains (AS) at } \\
\text { atrial contraction }\end{array}$} \\
\hline Basal AS (\%) & $21.3 \pm 8.8$ & $19.8 \pm 10.2$ & 0.60 \\
\hline Midatrial AS (\%) & $17.4 \pm 12.1$ & $25.3 \pm 13.3$ & 0.05 \\
\hline Apical AS (\%) & $21.5 \pm 29.1$ & $20.7 \pm 30.1$ & 0.93 \\
\hline
\end{tabular}

3D: three-dimensional; 3DS: three-dimensional strain; 3DSTE: three-dimensional speckle-tracking echocardiography; AS: area strain; CS: circumferential strain; LS: longitudinal strain; RS: radial strain.

("athlete's heart") from pathologic cardiac conditions. ${ }^{3}$ Regarding to D'Ascenzi et al. top-level athletes exhibit a dynamic morphological and functional LA remodeling, induced by training, with an increase in reservoir and conduit stroke volumes, but stable active stroke volume. ${ }^{16}$ Kasikcioglu et al. found that athletes (male endurance runners) had higher LA volume and volume index (except the conduit volume), PAEF and TAEF compared to control subjects. ${ }^{17}$ In contrast, increased LV-SV was associated with an increase in both PASV and AASV, and with unchanged LA emptying fractions in another study. These changes were thought to be normal physiologic adaptations to prolonged training. ${ }^{1}$ Our results are only partially in agreement with these findings demonstrating alterations in TASV, PASV, TAEF and AAEF with unchanged AASV and PAEF.

STE was used to measure peak atrial longitudinal strain (PALS) and peak atrial contraction strain (PACS) in studies by D'Ascenzi et al. ${ }^{4,18}$ They found reduced 


\section{COPYRIGHT $^{(} 2017$ EDIZIONI MINERVA MEDICA}

PALS and PACS in a mixed population of competitive athletes (volleyball, basketball, soccer), ${ }^{18}$ while when only elite soccer players were examined, significant reduction could be demonstrated only in PACS as compared to controls. ${ }^{4}$ In agreement with these findings, Gabrielli et al. have demonstrated decreased LA strain during active atrial contraction in professional handball players. ${ }^{19}$ However, in contrast, no differences in intrinsic atrial strain in any phases of LA function could be demonstrated between the following groups: high dynamic/high static and low-dynamic/high static elite male athletes and sedentary controls in another recent myocardial strain tracking imaging study. ${ }^{20}$ Our results confirmed reduction in strains featuring both LA reservoir and active contraction phases, but alterations in features of LA reservoir function proved to be more pronounced.

The peculiar pattern of LA dysfunction could be demonstrated in elite athletes in several studies. Regarding to the literature LA remodeling deemed to be a physiologic consequence of a global cardiac adaptation to the increased preload associated with intensive and chronic training. ${ }^{21}$ The role of LV (dys)function could also not be excluded. D'Ascenzi et al. concluded in a recent study, that a shift in the pattern of ventricular filling period toward early diastole could be demonstrated in elite soccer players leading to a more rapid passive atrial emptying. ${ }^{4}$ Moreover, the associated lower global LA active contraction may presumably be related to an increased myocardial distensibility at the end of diastole. 4, 22 Differences in volumetric and functional LA features between sports could be explained by different training volume, intensity, duration and type, but further studies are warranted to examine other sport-specific alterations.

3DSTE is a new promising tool based on blockmatching algorithm of the myocardial speckles, ${ }^{4}$ which just has been validated. 23,24 One of the major advantage of 3DSTE, that all LA volumetric, volume-based and strain parameters could be calculated from the same 3D acquired dataset making the whole procedure very easy to perform. ${ }^{11}$ Recently, increased LA volumes and specific alterations in functional properties could be demonstrated by 3DSTE in atrial fibrillation, ${ }^{25,} 26$ hypertrophic 11 and noncompaction cardiomyopathies, ${ }^{27}$ type 1 diabetes mellitus 12 and hypereosinophilic syndrome. ${ }^{28}$ Our results confirm feasibility of this new non-invasive
3DSTE methodology in competitive athletes and its usefulness to assess LA volumes, function and deformation and to understand the phsysiology of 'athlete's heart.

\section{Limitations of the study}

The present study should be considered as a preliminary observational study, not a validation study. ${ }^{23,} 24$ 3DSTE is a relatively new methodology with its specific limitations (for instance low spatial and temporal resolution, etc.), which facts should be considered when interpreting results. Another limitation is the relatively small population of athletes and matched controls. Finally, functional characterization of ventricles and right atrium was not aimed in this study.

\section{Conclusions}

3DSTE-derived increased cyclic LA volumes and specific alterations in LA functional properties could be demonstrated in young competing athletes which is most likely a physiologic consequence of a global cardiac adaptation to intensive and chronic training.

\section{References}

1. Erol MK, Ugur M, Yilmaz M, Acikel M, Sevimli S, Alp N. Left atrial mechanical functions in elite male athletes. Am J Cardiol 2001;88:915-7.A9

2. Shapiro LM. The morphologic consequences of systemic training. Cardiol Clin 1997; 15:373-9.

3. Pelliccia A, Maron BJ, Di Paolo FM, Biffi A, Quattrini FM, Pisicchio $\mathrm{C}$, et al. Prevalence and clinical significance of left atrial remodeling in competitive athletes. J Am Coll Cardiol 2005;46:690-6.

4. D'Ascenzi F, Cameli M, Zacà V, Lisi M, Santoro A, Causarano A, et al. Supernormal diastolic function and role of left atrial myocardial deformation analysis by 2D speckle tracking echocardiography in elite soccer players. Echocardiography 2011;28:320-6.

5. D’Ascenzi F, Pelliccia A, Natali BM, Zacà V, Cameli M, Alvino F, et al. Morphological and functional adaptation of left and right atria induced by training in highly trained female athletes. Circ Cardiovasc Imaging 2014;7:222-9.

6. Nemes A, Kalapos A, Domsik P, Forster T. Three-dimensional speckle-tracking echocardiography -- a further step in non-invasive threedimensional cardiac imaging. Orv Hetil 2012;153:1570-7.

7. D'Ascenzi F, Pelliccia A, Corrado D, Cameli M, Curci V, Alvino F, et al. Right ventricular remodelling induced by exercise training in competitive athletes Eur Heart J Cardiovasc Imaging 2016;17:301-7.

8. Devereux RB. Detection of left ventricular hypertrophy by M-mode echocardiography. Anatomic validation, standardization, and comparison to other methods. Hypertension 1987;9(2 Pt 2):II19-26.

9. Mitchell JH, Haskell W, Snell P, van Camp SP. Task force 8: Classification of sports. J Am Coll Cardiol 2005;45:1364-7.

10. Lang RM, Badano LP, Mor-Avi V, Afilalo J, Armstrong A, Ernande $\mathrm{L}$, et al. Recommendations for cardiac chamber quantification by 


\section{COPYRIGHT $^{\odot} 2017$ EDIZIONI MINERVA MEDICA}

NEMES

THE MAGYAR-SPORT STUDY

echocardiography in adults: an update from the American Society of Echocardiography and the European Association of Cardiovascular Imaging. Eur Heart J Cardiovasc Imaging 2015;16:233-70.

11. Domsik P, Kalapos A, Chadaide S, Sepp R, Hausinger P, Forster T, et al. Three-dimensional speckle tracking echocardiography allows detailed evaluation of left atrial function in hypertrophic cardiomyopathy - Insights from the MAGYAR-Path Study. Echocardiography 2014;31:1245-52.

12. Nemes A, Piros GA, Lengyel C, Domsik P, Kalapos A, Várkonyi TT, et al. Complex evaluation of left atrial dysfunction in patients with type 1 diabetes mellitus by three-dimensional speckle tracking echocardiography - Results from the MAGYAR-Path Study. Anatol J Cardiol 2016;16:587-93.

13. Nemes A, Forster T. Assessment of left atrial size and function -from M-mode to 3D speckle-tracking echocardiography. Orv Hetil 2014; 155:1624-31.

14. Höglund C. Enlarged left atrial dimension in former endurance athletes: an echocardiographic study. Int J Sports Med 1986;7:133-6.

15. D'Andrea A, Riegler L, Cocchia R, Scarafile R, Salerno G, Gravino $\mathrm{R}$, et al. Left atrial volume index in highly trained athletes. Am Heart J 2010;159:1155-61.

16. D’Ascenzi F, Pelliccia A, Natali BM, Cameli M, Lisi M, Focardi M, et al. Training-induced dynamic changes in left atrial reservoir, conduit, and active volumes in professional soccer players. Eur J Appl Physiol 2015;115:1715-23.

17. Kasikcioglu E, Oflaz H, Akhan H, Kayserilioglu A, Umman B, Bugra $\mathrm{Z}$, et al. Left atrial geometric and functional remodeling in athletes. Int J Sports Med 2006;27:267-71.

18. D’Ascenzi F, Pelliccia A, Natali BM, Cameli M, Andrei V, Incampo $\mathrm{E}$, et al. Increased left atrial size is associated with reduced atrial stiffness and preserved reservoir function in athlete's heart. Int J Cardiovasc Imaging 2015;31:699-705.

19. Gabrielli L, Bijnens BH, Butakoff C, Duchateau N, Montserrat S, Merino $\mathrm{B}$, et al. Atrial functional and geometrical remodeling in highly trained male athletes: for better or worse? Eur J Appl Physiol 2014; $114: 1143-52$

20. McClean G, George K, Lord R, Utomi V, Jones N, Somauroo J, et al. Chronic adaptation of atrial structure and function in elite male athletes. Eur Heart J Cardiovasc Imaging 2015;16:417-22.

21. Pelliccia A, Culasso F, Di Paolo FM, Marin BJ. Physiologic left ventricular cavity dilatation in elite athletes. Ann Intern Med 1999;130:23-31

22. Claessens PJ, Claessens CW, Claessens MM, Claessens MC, Claessens JE. Supernormal left ventricular diastolic function in triathletes. Tex Heart Inst J 2001;28:102-10.

23. Nemes A, Domsik P, Kalapos A, Lengyel C, Orosz A, Forster T. Comparison of three-dimensional speckle tracking echocardiography and two-dimensional echocardiography for evaluation of left atrial size and function in healthy volunteers (results from the MAGYARHealthy study). Echocardiography 2014:31:865-71.

24. Nagaya M, Kawasaki M, Tanaka R, Onishi N, Sato N, Ono K, et al. Quantitative validation of left atrial structure and function by two-dimensional and three-dimensional speckle tracking echocardiography: A comparative study with three-dimensional computed tomography. J Cardiol 2013;62:188-94.

25. Mochizuki A, Yuda S, Oi Y, Kawamukai M, Nishida J, Kouzu H, et al. Assessment of left atrial deformation and synchrony by threedimensional speckle-tracking echocardiography: comparative studies in healthy subjects and patients with atrial fibrillation. J Am Soc Echocardiogr 2013;26:165-74.

26. Chadaide S, Domsik P, Kalapos A, Sághy L, Forster T, Nemes A. Three-Dimensional Speckle Tracking Echocardiography-Derived Left Atrial Strain Parameters Are Reduced in Patients with Atrial Fibrillation (Results from the MAGYAR-Path Study). Echocardiography 2013;30:1078-83.

27. Nemes A, Piros GA, Domsik P, Kalapos A, Forster T. Left atrial volumetric and strain analysis by three-dimensional speckle tracking echocardiography in noncompaction cardiomyopathy - Results from the MAGYAR-Path Study. Hellenic J Cardiol 2016;57:23-9.

28. Nemes A, Marton I, Domsik P, Kalapos A, Pósfai É, Modok S, et al. Characterization of left atrial dysfunction in hypereosinophilic syndrome - Insights from the Motion analysis of the heart and great vessels by three-dimensional speckle tracking echocardiography in pathological cases (MAGYAR-Path) Study. Rev Port Cardiol $2016 ; 35: 277-83$

Funding.-This publication/research has been supported by the project TÁMOP-4.2.1.E-15/1/KONV-2015-0002.

Conflicts of interest.-The authors certify that there is no conflict of interest with any financial organization regarding the material discussed in the manuscript. Article first published online: May 3, 2016. - Manuscript accepted: May 2, 2016. - Manuscript revised: April 28, 2016. - Manuscript received: November 2, 2015. 